\title{
Influence of Sc on Microstructure and Mechanical Properties of High Zn-Containing Mg Alloy
}

\author{
Lidong Wang, ${ }^{1,2}$ Jie Yang, ${ }^{2}$ Limin Wang, ${ }^{2}$ and Zhanyi Cao' \\ ${ }^{1}$ Key Laboratory of Automobile Materials, Ministry of Education, Jilin University, \\ Changchun 130025, China \\ ${ }^{2}$ State Key Laboratory of Rare Earth Resource Utilization, Changchun Institute of Applied Chemistry, \\ Chinese Academy of Sciences, Changchun 130022, China \\ Correspondence should be addressed to Lidong Wang; ldwang@ciac.ac.cn and Zhanyi Cao; caozy@jlu.edu.cn
}

Received 1 September 2014; Revised 28 November 2014; Accepted 2 December 2014; Published 18 December 2014

Academic Editor: Jie Dai

Copyright (C) 2014 Lidong Wang et al. This is an open access article distributed under the Creative Commons Attribution License, which permits unrestricted use, distribution, and reproduction in any medium, provided the original work is properly cited.

Microstructures and mechanical properties of Mg-11Zn and Mg-11Zn-1Sc (wt\%) alloys were investigated. The main secondary phase of Mg-11Zn and Mg-11Zn-1Sc alloys is $\mathrm{MgZn}_{2}$ phase. Rare earth Sc element is an effective grain refiner and the grain size of $\mathrm{Mg}-11 \mathrm{Zn}-1 \mathrm{Sc}$ alloy is greatly refined. The mechanical properties of the $\mathrm{Mg}-11 \mathrm{Zn}$ alloy were greatly improved with incorporation of $1 \mathrm{wt} \% \mathrm{Sc}$, especially for the elevated temperature strength. Such mechanical property enhancement is ascribed to the refinement and pinning mechanism of high heat-resistant Sc and Sc-containing intermetallic particles in $\mathrm{Mg}$ alloy.

\section{Introduction}

$\mathrm{Mg}$ is the lightest structural metal and exhibits many good properties, such as high specific strength and stiffness, machinability, and impact and dent resistance. However, its poor mechanical properties, especially low strength, hamper its widespread applications. Zn and rare earths, as important alloying elements, are often added in Mg alloys to enhance their mechanical properties. Most research works involved with Mg-Zn-RE (rare earth) alloy system are focused on low $\mathrm{Zn}$ content $(<6 \mathrm{wt} \%)$ system and Mg-Zn-Y alloy is the most representative one [1-4]. High Zn content alloys have low production temperatures and good flowability, but relevant research is not comprehensive and most works are focused on the $\mathrm{Mg}-\mathrm{Al}-\mathrm{Zn}$ alloy system [5-7].

According to the Mg-Sc phase diagram, Sc has large solid solubility in $\alpha$-Mg matrix. Moreover, Sc can effectively improve the high temperature strength and creep resistance of Mg-RE-Sc alloys [8-10]. For these reasons, this paper concentrates on studying the influence of Sc on high Zn-containing $\mathrm{Mg}$ alloys.

\section{Experimental Procedure}

The nominal compositions of the investigated alloys are $\mathrm{Mg}$ $11 \mathrm{Zn}$ (in wt\%, alloy A) and Mg-11Zn-1Sc (in wt\%, alloy B). They were prepared from commercial pure $\mathrm{Mg}(>99.8 \mathrm{wt} \%)$, $\mathrm{Zn}$ (>99.95 wt\%), and Mg-Sc master alloy. The alloys were made by melting $\mathrm{Mg}$ in graphite crucible covered by antioxidizing flux in a furnace, and then $\mathrm{Zn}$ particles were added. The Mg-Sc master alloy was lastly added to the crucible. After stirring the molten alloy and setting for approximately $30 \mathrm{~min}$ at $720^{\circ} \mathrm{C}$ for homogenization, the alloy melt was casted into a copper mould at approximately $720^{\circ} \mathrm{C}$ and the size of the ingot is $70 \times 40 \times 13 \mathrm{~mm}^{3}$. Specimens were mechanically polished and then etched with picric acid-ethanol- $\mathrm{H}_{2} \mathrm{O}$ (for grain size observation) and $\mathrm{HNO}_{3}$-ethanol (for dendritic structure observation) solutions, respectively. Structures were observed by optical microscopy, transmission electron microscopy (TEM), scanning electron microscopy (SEM), and X-ray diffraction (XRD). Uniaxial tensile test was carried out at room temperature (RT), $200^{\circ} \mathrm{C}$, and $280^{\circ} \mathrm{C}$ under a strain rate of $1.52 \times 10^{-4} \mathrm{~s}^{-1}$ on dog bone specimens 


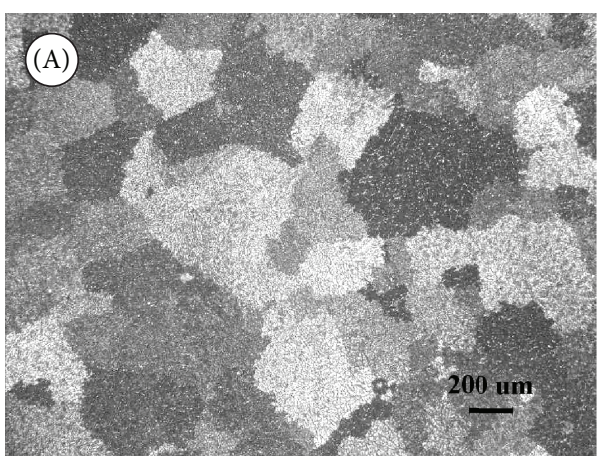

(a)

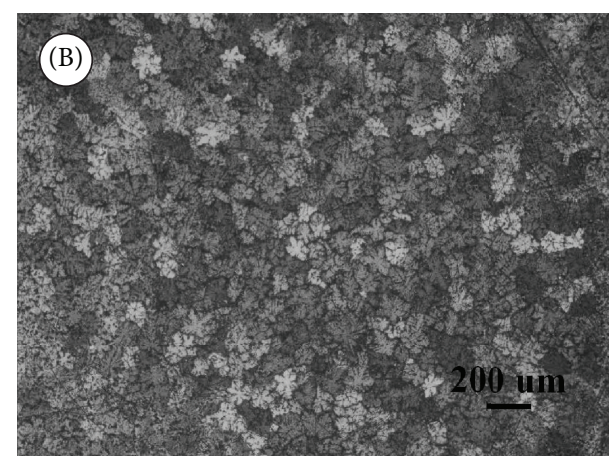

(b)

FIGURE 1: OMs of alloys A and B etched with picric acid-ethanol- $\mathrm{H}_{2} \mathrm{O}$ solution.

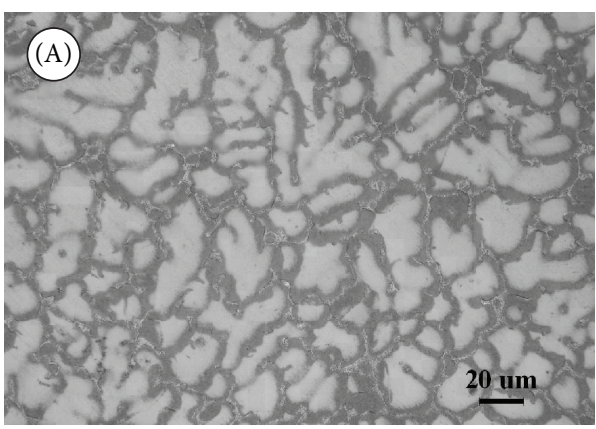

(a)

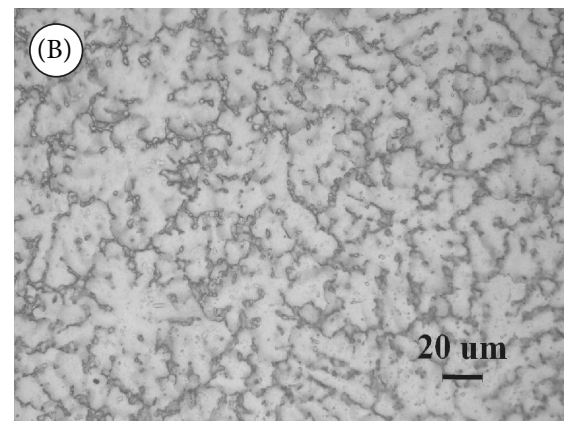

(b)

Figure 2: OMs of alloys A and $\mathrm{B}$ etched with $\mathrm{HNO}_{3}$-ethanol solution.

with nominal size of $11 \mathrm{~mm}$ in length, $3.5 \mathrm{~mm}$ in width, and $1.5 \mathrm{~mm}$ in thickness. For tensile test at elevated temperatures, the heating-plus-holding time was $10 \mathrm{~min}$ for the balance of temperature.

\section{Results and Discussion}

3.1. Microstructure. The optical micrographs (OM) of alloys $\mathrm{A}$ and $\mathrm{B}$ etched with picric acid-ethanol- $\mathrm{H}_{2} \mathrm{O}$ solution are shown in Figure 1. The average grain sizes of the two alloys are approximately 380 and $100 \mu \mathrm{m}$, respectively, which were calculated by the linearly intercepted method. Figure 2 illustrates the OMs of the two alloys etched with $\mathrm{HNO}_{3}$-ethanol solution, and the primary interdendritic spacing of the two alloys was calculated to be 16 and $9 \mu \mathrm{m}$, respectively. It indicates that both the grain size and the primary interdendritic spacing are refined by the addition of $1 \mathrm{wt} \% \mathrm{Sc}$. The refining effect on the grain size is much higher than that on the primary interdendritic spacing.

Generally, grain size can be refined via two ways. One is the addition of foreign nucleating agents such as $\mathrm{Zr}$ to increase the number of nuclei. The other is the presence of solute elements to enhance constitutional supercooling for activating nucleation. In the present work, on account of Sc quantity being only $1 \mathrm{wt} \%$ and having large solid solubility in the $\alpha-\mathrm{Mg}$ matrix, no enough Sc atoms were enriched and aggregated at the solid/liquid interface to result in the constitutional supercooling during the solidification process. The industrial grade $\mathrm{Mg}$ contains some impurity elements such as $\mathrm{Al}, \mathrm{Mn}$, and Fe. During the solidification process, Sc atoms are active and they quickly react with impurities to form intermetallic particles such as $\mathrm{Al}_{3} \mathrm{Sc}$ and $\mathrm{Mn}_{2} \mathrm{Sc}$. The Sc-containing intermetallic particles increase the number of nuclei. Similarly, Sc addition can refine grain size in ascast Mg-Gd [11] and ZK60 [12] alloys. A new group of Mg$\mathrm{RE}$ materials with $\mathrm{Mn}$ and Sc were developed and showed superior creep resistance, which reportedly results from the formation of a thermally stable $\mathrm{Mn}_{2} \mathrm{Sc}$ particles phase $[8,10]$. $\mathrm{Al}_{3} \mathrm{Sc}$ particles may serve as heterogeneous nuclei during solidification to refine the grain size in as-cast structure and improve mechanical properties by fine-grain strengthening in $\mathrm{Al}$ alloys $[13,14]$. Thus, the above literature findings support our hypothesis that Sc reacts with impurities to form Sccontaining intermetallic particles that result in an increase in the nuclei number, which is the main cause of grain size refining in alloy B.

The XRD analyses of the two alloys are given in Figure 3. Both the two alloys are composed of $\alpha-\mathrm{Mg}$ and $\mathrm{MgZn}_{2}$ phases. Generally, there are always RE-containing phases in the Mg-Zn-RE alloy system. However, no Sc-containing phases are observed in alloy B. Figure 4 displays the TEM image of alloy B, and rod-shaped precipitates are observed. 


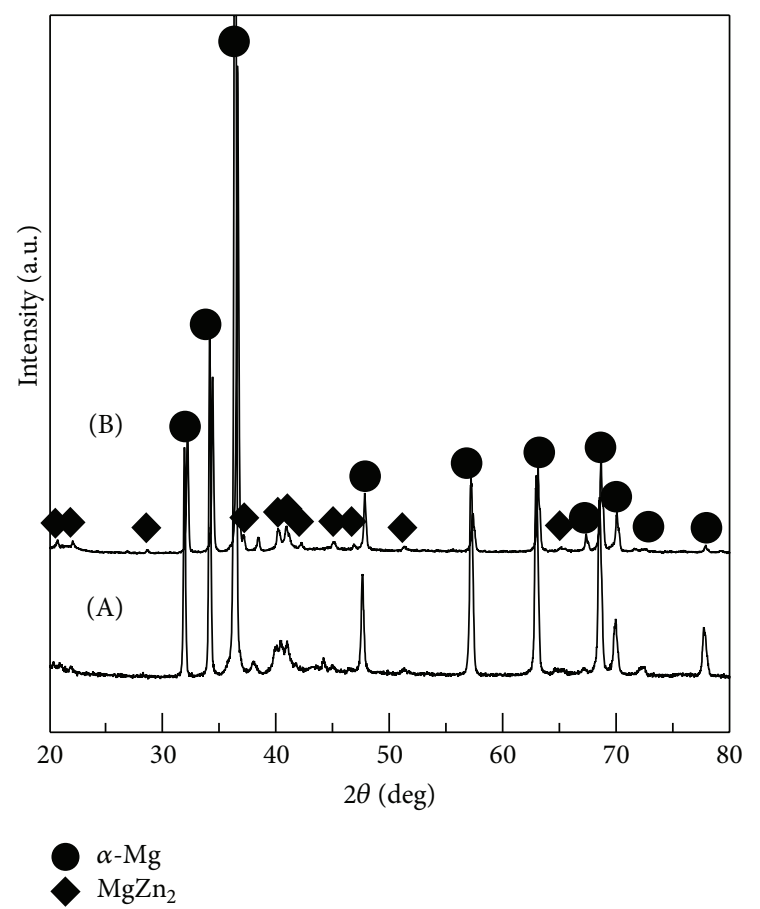

FIgURE 3: XRD patterns of alloys A and B.

TABLE 1: Metallic radius and electronegativity of the $\mathrm{Mg}, \mathrm{Zn}$, and Sc.

\begin{tabular}{lccc}
\hline Elements & $\mathrm{Mg}$ & $\mathrm{Sc}$ & $\mathrm{Zn}$ \\
\hline Atomic radius $(\mathrm{nm})$ & 0.1602 & 0.1641 & 0.153 \\
Electronegativity & 1.31 & 1.27 & 1.65 \\
\hline
\end{tabular}

The corresponding selected area diffraction pattern shows that these phases are $\mathrm{MgZn}_{2}$ phase. Their long axes are always parallel to the $[0001]_{\mathrm{Mg}}$ direction [15].

The XRD analysis indicates that alloy $\mathrm{B}$ interestingly consists of no Sc-containing phases, whereas when RE elements are added to $\mathrm{Mg}-\mathrm{Zn}$ alloy system, the RE and Zn will compete with each other to occupy the Mg crystal lattice, therefore decreasing each other's solubility limits in the $\alpha-\mathrm{Mg}$ matrix. Then, the RE, $\mathrm{Zn}$, and $\mathrm{Mg}$ elements will preferentially form binary or ternary RE-containing phases. For example, in $\mathrm{Mg}-\mathrm{Zn}$-Y alloy system, $\mathrm{Mg}_{3} \mathrm{Y}_{1} \mathrm{Zn}_{6}$ phase (Iphase) occurred when $Y$ was added to the Mg-Zn alloy,even if the $\mathrm{Y}$ content was less than $1 \mathrm{wt} \%$ [16]. Table 1 lists the metallic radius and electronegativity of $\mathrm{Mg}, \mathrm{Zn}$, and Sc elements [17]. Compared with $\mathrm{Zn}$, the metallic radius and electronegativity of Sc are closer to those of Mg. According to the principle of compatibility and similitude, Sc is superior to $\mathrm{Zn}$ for occupying the $\mathrm{Mg}$ crystal lattice and thus can readily be dissolved in the $\alpha-\mathrm{Mg}$ matrix. That explains why there is no Sc-containing phase found in alloy B.

3.2. Mechanical Properties. The tensile performance of alloys $\mathrm{A}$ and $\mathrm{B}$ was assessed in the temperature range from RT to $280^{\circ} \mathrm{C}$, and the representative stress-strain curves were shown in Figure 5. The corresponding mechanical properties, including the ultimate tensile stress $\left(\sigma_{b}\right), 0.2 \%$ yield stress

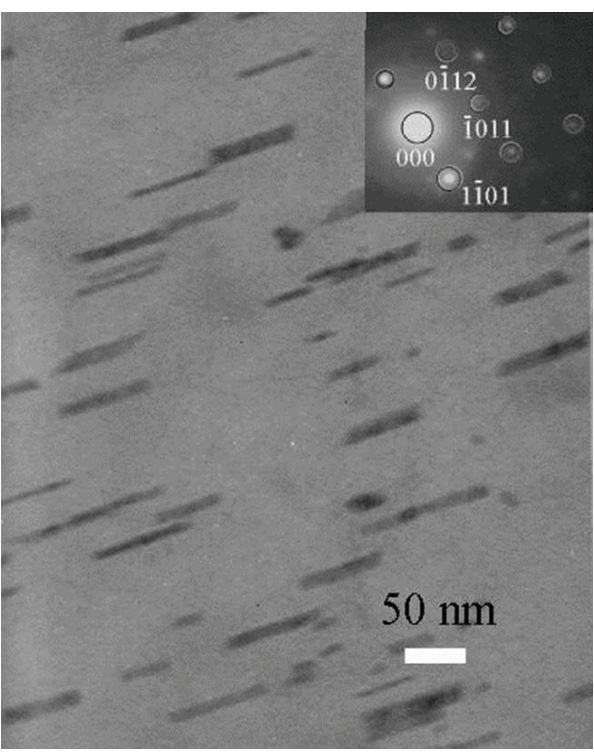

FIgURE 4: TEM image of alloy B.

$\left(\sigma_{0.2}\right)$, and elongation at failure $(\varepsilon)$, were listed in Table 2 . The RT $\sigma_{b}$ of the two alloys are almost the same, suggesting that Sc plays a minor role in improving the room temperature $\sigma_{b}$. However, the $\sigma_{0.2}$ is greatly enhanced by the addition of Sc. The $\sigma_{0.2}$ of alloy B is 1.4 times that of alloy $\mathrm{A}$, and the $\sigma_{0.2}$ increment is about $45 \mathrm{MPa}$. At $200^{\circ} \mathrm{C}$, the $\sigma_{b}$ and $\sigma_{0.2}$ of alloy $\mathrm{B}$ are 175 and $144 \mathrm{MPa}$, which are 1.9 and 1.7 times those of alloy A. At $280^{\circ} \mathrm{C}$, the $\sigma_{b}$ and $\sigma_{0.2}$ of alloy B are 2.7 and 4.6 times those of alloy $\mathrm{A}$. The above results indicate that $1 \mathrm{wt} \%$ Sc can effectively enhance the alloy's strength, especially for the yield strength at elevated temperatures.

The yield strength of metals and alloys varies with grain size, and the relationship usually follows the Hall-Petch equation [18]:

$$
\sigma=\sigma_{0}+k d^{-1 / 2}
$$

where $\sigma$ is the $0.2 \%$ yield stress $\left(\sigma_{0.2}, \mathrm{MPa}\right)$ and $d$ is a measure of grain size in $\mu \mathrm{m} . \sigma_{0}$ and $k$ are parameters determined for the polycrystalline material. In the current work, $\sigma_{0}$ is expected to be a constant value with consideration of the low Sc content. $k=300 \sqrt{\mu \mathrm{m}} \mathrm{MPa}$ has been used to evaluate the Hall-Petch effects in the Mg-(0.2 2.4)at\% $\mathrm{Zn}$ alloy system [19]. Thus, this value will also be employed in the present work to estimate the grain size effect on the yield strength. According to the Hall-Petch equation, as a reduction in grain size from $380 \mu \mathrm{m}$ to $100 \mu \mathrm{m}$, alloy B is expected to have a $\sigma_{0.2}$ increment of about $15 \mathrm{MPa}$ at RT. This value is much smaller than the experimental value of $45 \mathrm{MPa}$. Therefore, the $\sigma_{0.2}$ increment does not solely depend on the grain refining effect, and other influencing factors should also be considered. Sc is solid solvated in the matrix and thus can strengthen the alloy by solution hardening. It is known that dislocation slipping and pile-up lead to crack initiations, and then the cracks propagate and result in final fracture during tensile test. The Sc-containing intermetallic particles disperse homogeneously in the Mg matrix, which is beneficial to hinder 
TABLE 2: Tensile properties of alloys A and B at RT, $200^{\circ} \mathrm{C}$, and $280^{\circ} \mathrm{C}$.

\begin{tabular}{lccccccccc}
\hline Alloys & \multicolumn{3}{c}{$\sigma_{b}(\mathrm{MPa})$} & \multicolumn{3}{c}{$\sigma_{0.2}(\mathrm{MPa})$} & \multicolumn{2}{c}{$(\%)$} \\
$\mathrm{RT}$ & $200^{\circ} \mathrm{C}$ & $280^{\circ} \mathrm{C}$ & $\mathrm{RT}$ & $200^{\circ} \mathrm{C}$ & $280^{\circ} \mathrm{C}$ & $\mathrm{RT}$ & $200^{\circ} \mathrm{C}$ & $280^{\circ} \mathrm{C}$ \\
\hline (A) & 217 & 91 & 45 & 118 & 83 & 22 & 8.7 & 32.3 \\
(B) & 227 & 175 & 120 & 163 & 144 & 102 & 5.0 & 14.1 \\
\hline
\end{tabular}

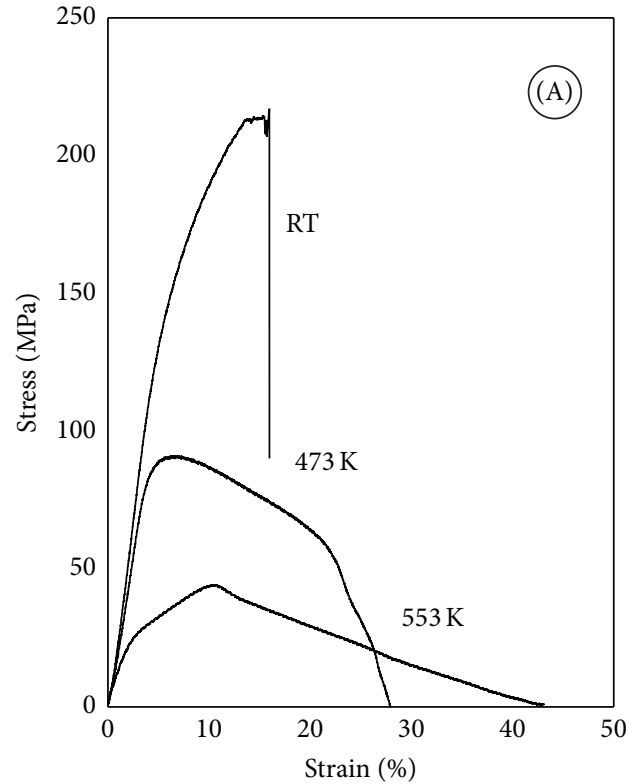

(a)

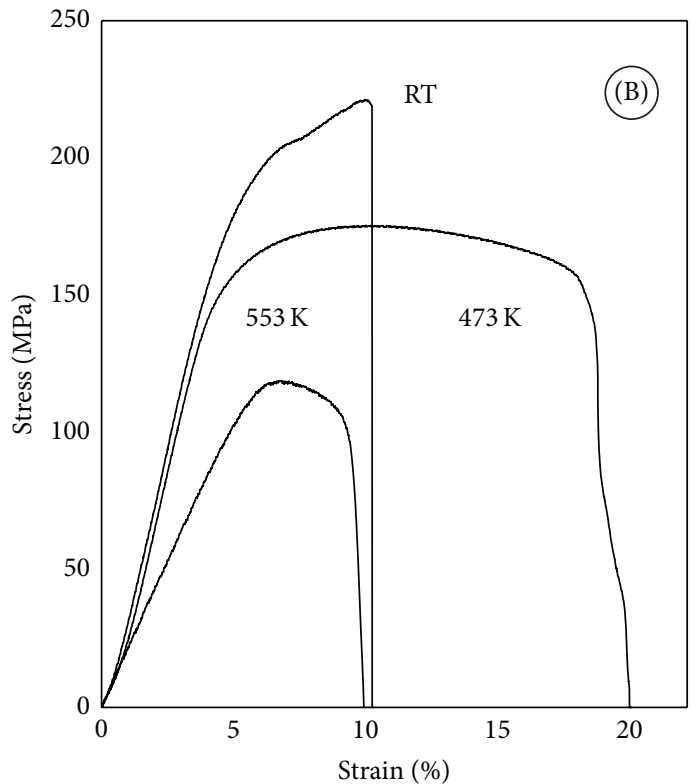

(b)

Figure 5: Stress-strain curves of alloys A and B at RT, $200^{\circ} \mathrm{C}$, and $280^{\circ} \mathrm{C}$.

dislocation slipping, disperse dislocations, and weaken their pile-up, and thus, the strengths of the alloy are reinforced. The pinning mechanism of Sc-containing intermetallic particles results in dislocation slipping weakening and ductility decrease of alloy B at RT and elevated temperature.

When test temperature rises, dislocation slipping and pile-up accelerate and grain boundaries soften. If dislocations gather at grain boundary, the alloy's strength will rapidly deteriorate. In alloy $\mathrm{B}$, the finer gain size means higher content of grain boundary, which is not beneficial to enhancing the strength of the alloy at elevated temperature. It is believed that there are two reasons for high temperature strengthening of $\mathrm{Sc}$ added alloy. One is that $\mathrm{Sc}$ can increase the melting point of the Mg-Sc solid solution [8]. The other is that the pinning mechanism of high melting point Sc-containing intermetallic particles can remarkably hinder dislocation slipping and gather at grain boundary. The similar phenomenon has been reported in Mg-Sc-RE alloys [10] that thermally stable particles are strong obstacles to dislocation slipping.

\section{Conclusions}

The grain size of the Mg-11Zn alloy was greatly refined with Sc element. The refinement mechanism of $S c$ is that $S c$ reacts with impurities to generate Sc-containing intermetallic particles, which increase the nuclei number. The yield strength and ultimate tensile strength of the $\mathrm{Mg}$ alloy are greatly improved by Sc element at RT mainly due to the fine-grain strengthening effect and the dissolved strengthening effect of Sc element. The higher elevated temperature strength of alloy B is attributed to Sc induced melting point increase of Mg-Sc solid solution and the pinning mechanism of high melting point Sc-containing intermetallic particles to hinder dislocation slipping.

\section{Conflict of Interests}

The authors declare that there is no conflict of interests regarding to the publication of this paper.

\section{Acknowledgments}

This work is financially supported by the Foundation for Innovative Research Groups of the National Natural Science Foundation (20921002), the National Natural Science Foundation of China (21221061), the Science and Technology Program of Jilin Province (201105007), and the Science and Technology Support Project of Jilin Province (20140325003GX).

\section{References}

[1] D. K. Xu, W. N. Tang, L. Liu, Y. B. Xu, and E. H. Han, "Effect of $\mathrm{Y}$ concentration on the microstructure and mechanical 
properties of as-cast Mg-Zn-Y-Zr alloys," Journal of Alloys and Compounds, vol. 432, no. 1-2, pp. 129-134, 2007.

[2] Q. Li, Q. Wang, Y. Wang, X. Zeng, and W. Ding, "Effect of Nd and $\mathrm{Y}$ addition on microstructure and mechanical properties of as-cast Mg-Zn-Zr alloy," Journal of Alloys and Compounds, vol. 427, no. 1-2, pp. 115-123, 2007.

[3] Y. Wang, G. Wu, W. Liu, S. Pang, Y. Zhang, and W. Ding, "Effects of chemical composition on the microstructure and mechanical properties of gravity cast $\mathrm{Mg}-\mathrm{xZn}-\mathrm{yRE}-\mathrm{Zr}$ alloy," Materials Science and Engineering A, vol. 594, pp. 52-61, 2014.

[4] Q. C. Le, Z. Q. Zhang, Z. W. Shao, J. Z. Cui, and Y. Xie, "Microstructures and mechanical properties of $\mathrm{Mg}-2 \% \mathrm{Zn}-0.4 \% \mathrm{RE}$ alloys," Transactions of Nonferrous Metals Society of China, vol. 20, pp. 352-356, 2010.

[5] Y. Liu, M. Qian, and Z. Fan, "Microstructure and mechanical properties of a Rheo-diecast Mg-10Zn-4.5Al alloy," Materials Transactions, vol. 46, no. 10, pp. 2221-2228, 2005.

[6] I. N. G. Antara, K. Suzuki, T. Kayuta, S. Kamado, and Y. Kojima, "Application of semi-solid forming to magnesium alloys with high $\mathrm{Al}$ and $\mathrm{Zn}$ contents," Materials Science Forum, vol. 419422, pp. 629-634, 2003.

[7] X. C. Wan, H. J. Ni, M. Y. H. Hang, H. L. Zhang, and J. H. Sun, "Microstructure, mechanical properties and creep resistance of $\mathrm{Mg}-(8 \%-12 \%) \mathrm{Zn}-(2 \%-6 \%) \mathrm{Al}$ alloys," Transactions of Nonferrous Metals Society of China, vol. 23, pp. 896-903, 2013.

[8] F. Von Buch, J. Lietzau, B. L. Mordike, A. Pisch, and R. SchmidFetzer, "Development of Mg-Sc-Mn alloys," Materials Science and Engineering A, vol. 263, no. 1, pp. 1-7, 1999.

[9] B. L. Mordike, "Development of highly creep resistant magnesium alloys," Journal of Materials Processing Technology, vol. 117, no. 3, pp. 391-394, 2001.

[10] B. L. Mordike, I. Stulíková, and B. Smola, "Mechanisms of creep deformation in Mg-Sc-based alloys," Metallurgical and Materials Transactions A: Physical Metallurgy and Materials Science, vol. 36, no. 7, pp. 1729-1736, 2005.

[11] X. Y. Fang, D. Q. Yi, and J. F. Nie, "Influence of solution treatments on the age-hardening response of $\mathrm{Mg}-\mathrm{Gd}(-\mathrm{Mn}-\mathrm{Sc})$ alloys," Journal of Alloys and Compounds, vol. 486, no. 1-2, pp. 900-904, 2009.

[12] T. T. Liu, F. S. Pan, and X. Y. Zhang, "Effect of Sc addition on the work-hardening behavior of ZK60 magnesium alloy," Materials \& Design, vol. 43, pp. 572-577, 2013.

[13] J. Z. Dang, Y. F. Huang, and J. Cheng, "Effect of Sc and Zr on microstructures and mechanical properties of as-cast AlMg-Si-Mn alloys," Transactions of Nonferrous Metals Society of China, vol. 19, no. 3, pp. 540-544, 2009.

[14] S. Costa, H. Puga, J. Barbosa, and A. M. P. Pinto, "The effect of Sc additions on the microstructure and age hardening behaviour of as cast Al-Sc alloys," Materials and Design, vol. 42, pp. 347-352, 2012.

[15] J. S. Chun and J. G. Byrne, "Precipitate strengthening mechanisms in magnesium zinc alloy single crystals," Journal of Materials Science, vol. 4, no. 10, pp. 861-872, 1969.

[16] Y. Zhang, X. Zeng, L. Liu et al., "Effects of yttrium on microstructure and mechanical properties of hot-extruded Mg-ZnY-Zr alloys," Materials Science and Engineering A, vol. 373, no. 1-2, pp. 320-327, 2004.

[17] L. L. Rokhlin, Magnesium Alloys Containing Rare Earth Metals, Structure and Properties, Taylor \& Francis, London, UK, 2003.

[18] A. Singh, M. Watanabe, A. Kato, and A. P. Tsai, "Microstructure and strength of quasicrystal containing extruded $\mathrm{Mg}-\mathrm{Zn}-\mathrm{Y}$ alloys for elevated temperature application," Materials Science and Engineering A, vol. 385, no. 1-2, pp. 382-396, 2004.

[19] C. H. Cáceres and A. Blake, "The strength of concentrated MgZn solid solutions," Physica Status Solidi (a), vol. 194, no. 1, pp. 147-158, 2002. 

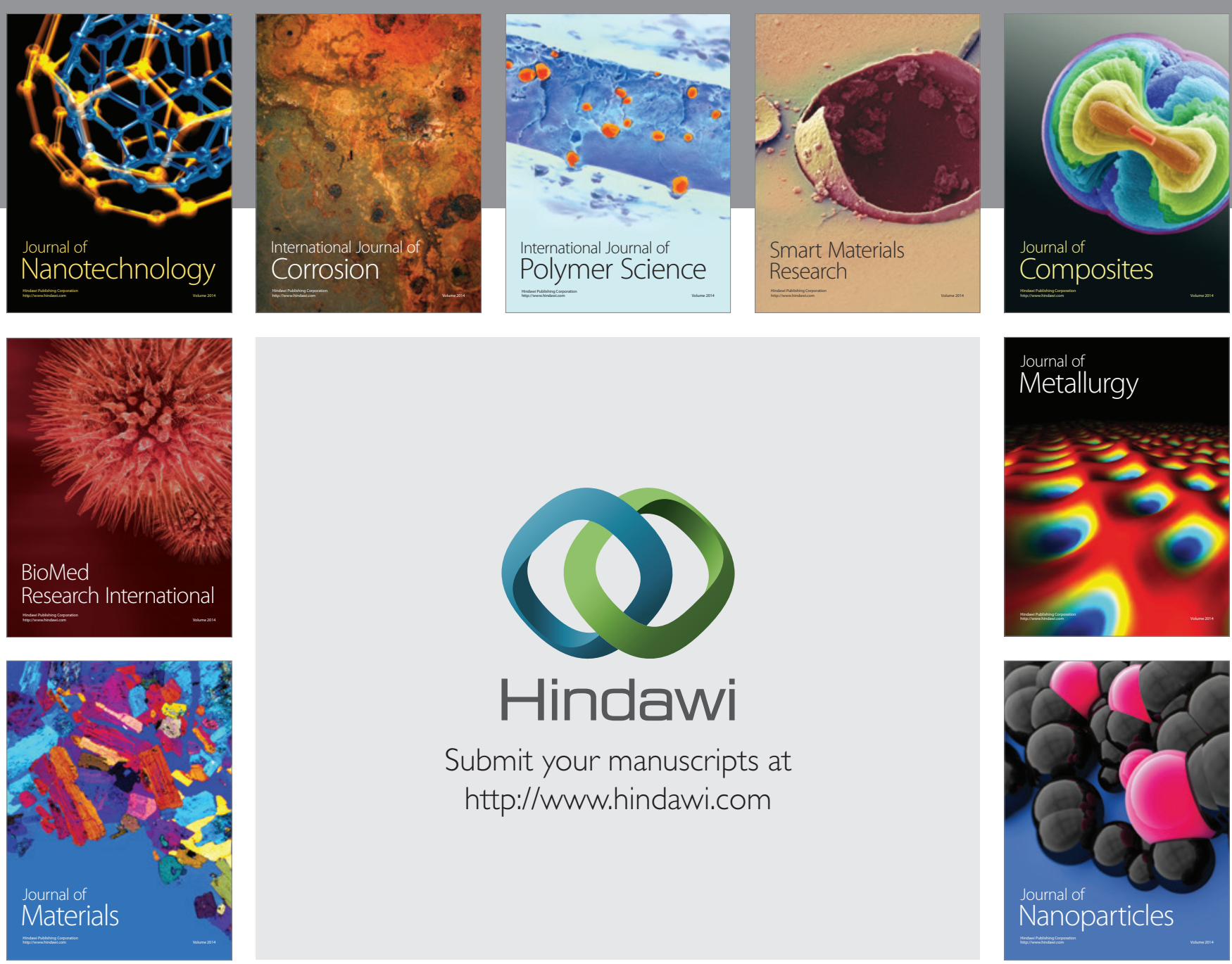

Submit your manuscripts at http://www.hindawi.com
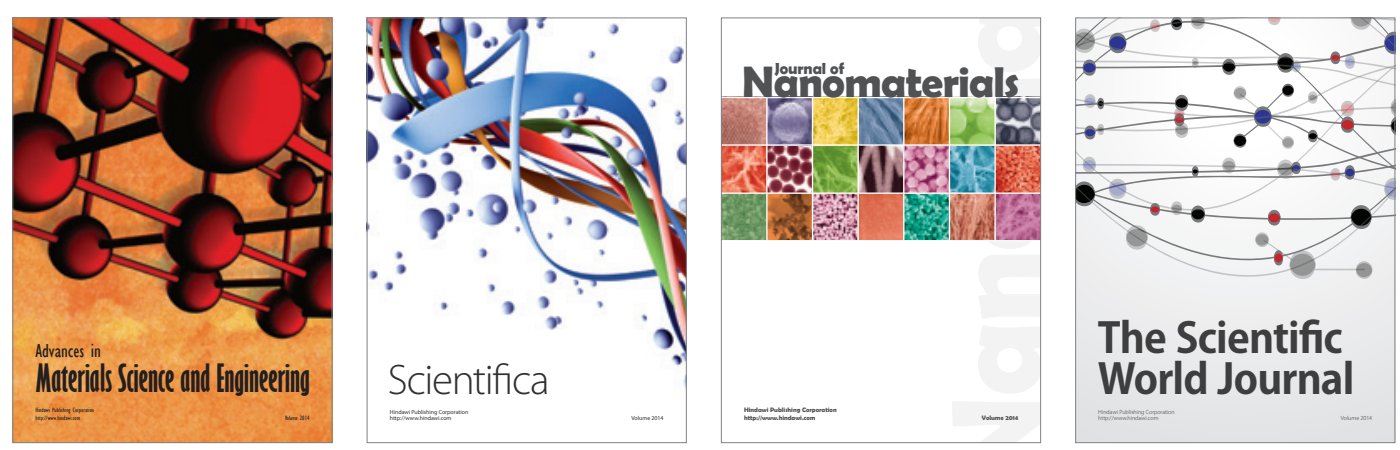

\section{The Scientific World Journal}
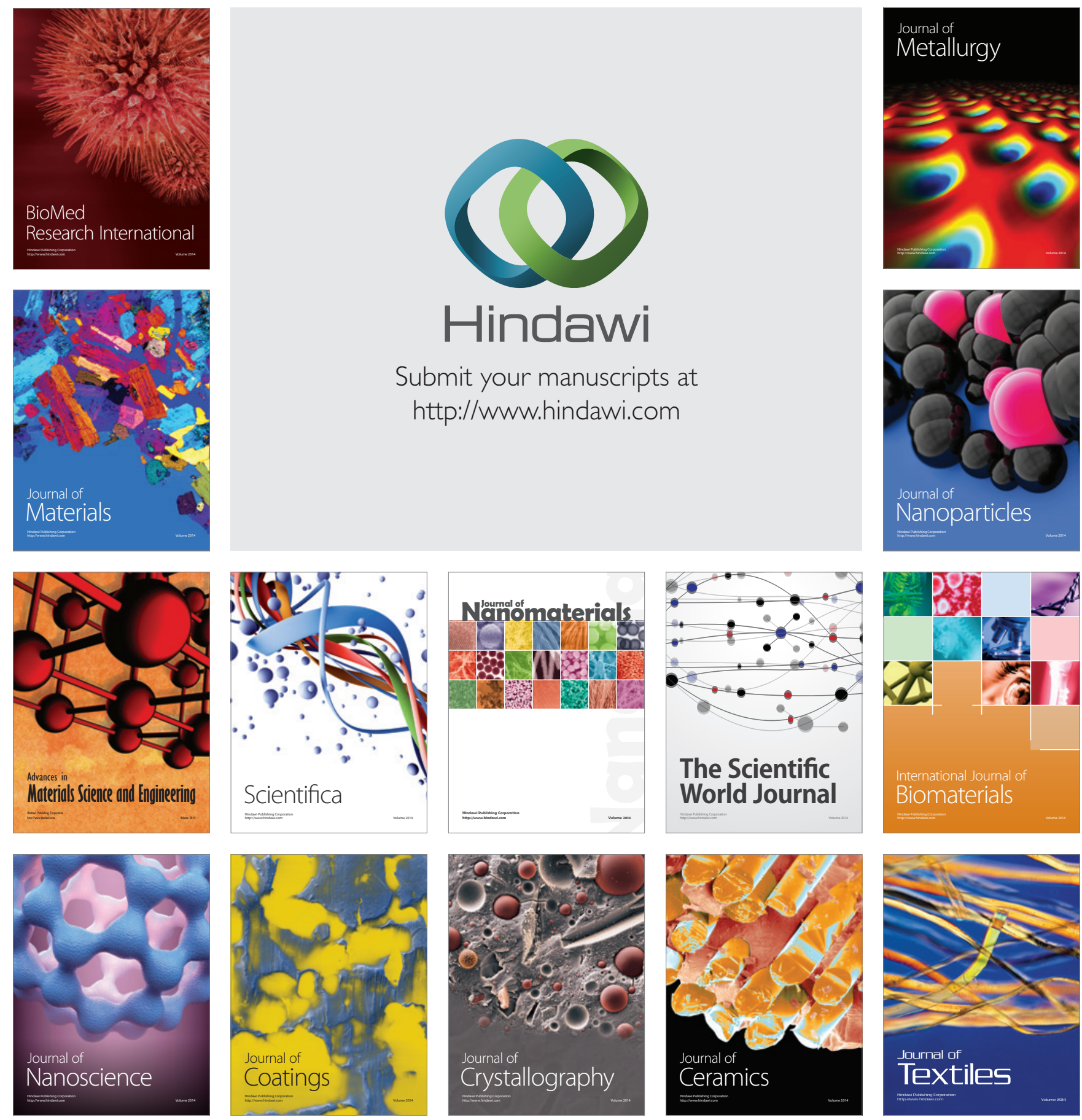